\title{
Part II. Mitochondrial mutational status of high nitric oxide adapted cell line BT-20 (BT-20-HNO) as it relates to human primary breast tumors
}

\author{
H. De Vitto • B. S. Mendonça • K. M. Elseth • \\ B. J. Vesper - E. A. Portari • C. V. M. Gallo • \\ W. A. Paradise • F. D. Rumjanek • J. A. Radosevich
}

Received: 27 June 2012 / Accepted: 4 October 2012 /Published online: 14 December 2012

(C) International Society of Oncology and BioMarkers (ISOBM) 2012

\begin{abstract}
Mitochondria combine hydrogen and oxygen to produce heat and adenosine triphosphate (ATP). As a toxic by-product of oxidative phosphorylation (OXPHOS), mitochondria generate reactive oxygen species (ROS). These free radicals may cause damage to mitochondrial DNA (mtDNA) and other molecules in the cell. Nitric oxide (NO) plays an important role in the biology of human cancers, including
\end{abstract}

H. De Vitto · B. S. Mendonça • F. D. Rumjanek

Universidade Federal do Rio de Janeiro, IBqM,

Rio de Janeiro, Brazil

H. De Vitto $\cdot$ K. M. Elseth • B. J. Vesper • W. A. Paradise $\cdot$

J. A. Radosevich $(\square)$

Center for Molecular Biology of Oral Diseases,

College of Dentistry, University of Illinois at Chicago,

801 S. Paulina St.,

Chicago, IL 60612, USA

e-mail: jrados@uic.edu

H. De Vitto $\cdot$ K. M. Elseth • B. J. Vesper · J. A. Radosevich Jesse Brown VAMC,

Chicago, IL, USA

H. De Vitto - K. M. Elseth • B. J. Vesper • W. A. Paradise • J. A. Radosevich

Department of Oral Medicine and Diagnostic Sciences, College of Dentistry, University of Illinois at Chicago,

Chicago, IL, USA

\section{E. A. Portari}

Instituto Fernandes Figueira, FIOCRUZ,

Rio de Janeiro, Brazil

C. V. M. Gallo

Universidade do Estado do Rio de Janeiro, IB, DECB,

Rio de Janeiro, Brazil breast cancer; however, it is still unclear how NO might affect the mitochondrial genome. The aim of the current study is to determine the role of mtDNA in the breast oncogenic process. Using DNA sequencing, we studied one breast cancer cell line as a model system to investigate the effects of oxidative stress. The BT-20 cell line was fully adapted to increasing concentrations of the NO donor DETA-NONOate and is referred to as BT-20-HNO, a high NO (HNO) cell line. The HNO cell line is biologically different from the "parent" cell line from which it originated. Moreover, we investigated 71 breast cancer biopsies and the corresponding noncancerous breast tissues. The free radical $\mathrm{NO}$ was able to generate somatic mtDNA mutations in the BT-20-HNO cell line that were missing in the BT20 parent cell line. We identified two somatic mutations, A4767G and G13481A, which changed the amino acid residues. Another two point mutations were identified in the mtDNA initiation replication site at nucleotide 57 and at the 'hot spot' cytidine-rich D300-310 segment. Furthermore, the NO regulated the mtDNA copy number and selected different mtDNA populations by clonal expansion. Interestingly, we identified eight somatic mutations in the coding regions of mtDNAs of eight breast cancer patients $(8 / 71,11.2 \%)$. All of these somatic mutations changed amino acid residues in the highly conserved regions of mtDNA which potentially leads to mitochondrial dysfunctions. The other two somatic mtDNA mutations in the displacement loop (D-loop) region [303:315 $\mathrm{C}(7-8) \mathrm{TC}(6)$ and nucleotide 57] were distributed among 14 patients (14/71, $19.7 \%$ ). Importantly, of these 14 patients, six had mutations in the $p 53$ gene. These results validate the BT-20 parent/HNO cell line model system as a means to study ROS damage in mtDNA, as it parallels the results found in a subset of the patient population. 
Keywords Breast cancer - Somatic mtDNA mutations . mtDNA copy number $\cdot$ Nitric oxide $(\mathrm{NO}) \cdot \mathrm{NADH}$ dehydrogenase (complex I)

\section{Introduction}

Mitochondria are major sources of reactive oxygen species (ROS) production. ROS have been associated with diverse cellular processes such as apoptosis, metastasis, and signal transduction for cell proliferation [1, 2]. These processes demonstrate that mitochondria are essential for maintaining the health of an organism [3]. Studying the role of ROS in cellular functions will lead to a better understanding of the cellular oxidative/reductive (redox) signaling; these signaling processes have been linked to a number of mitochondria metabolism defects, including (1) age-related disorders [4], (2) degenerative diseases [5], and (3) various forms of cancer [6-8].

Nitric oxide (NO), a free radical, has been associated in many different physiological and pathophysiological processes of human diseases. NO is a natural product that is overproduced by a variety of human tumors, including breast tumors [9-12]. Upregulation of NO production may affect the redox state of cells [13], and a wide spectrum of NO expression has been noted in various patient populations. It is well established that high $\mathrm{NO}(\mathrm{HNO})$ expression correlates with a diminished outcome, whereas low expression correlates to better treatment response and patient outcomes [14]. Because NO is a natural product and because of the patient correlations previously reported, we used NO to adapt the BT20 cell line to comparatively high levels of NO. The biological function of NO is highly concentration-dependent [15]. At low levels, $\mathrm{NO}$ acts as an antitumoral inflammatory response; however, at high levels, NO has been shown to cause mutational events which may lead to cancer [16, 17].

DNA damage by redox activity has been shown to be a significant contributor to the progression of cancer $[18,19]$. Some studies have reported that somatic mutation in mitochondrial DNA (mtDNA) contributes to initiation and progression of various human cancers. These studies show the importance of studying mtDNA in tumorigenesis. It has been shown that two or more mtDNA populations, wild type and mutant, coexist in early tumor cell development, and thereafter, mutant populations are clonally selected enough to result in the anomalous genome to lead to cellular transformation [20].

The mtDNA encodes 13 polypeptides, seven (ND1, 2, 3, $4 \mathrm{~L}, 4,5$, and 6 ) of the 45 polypeptides of Complex I, one (cytochrome $b$, cytb) of the 11 polypeptides of Complex III, three (COI, II, an III) of the 13 polypeptides of Complex IV, and two (ATP6 and ATP8) of the approximately 17 polypeptides of Complex V. mtDNA also encodes $12 \mathrm{~S}$ and 16S rRNA, as well as 22 transfer RNAs [21]. All 13 mtDNA genes that encode proteins are central to the mitochondrial energy production process, oxidative phosphorylation (OXPHOS), since these 13 proteins function as the central electron and proton wires for energy production by complexes I, III, IV, and $\mathrm{V}$ [21]. The mtDNA has a small region, $1.1 \mathrm{~kb}$ in size, called the displacement loop (D-loop) that controls both mitochondrial replication and transcription. The D-loop region has been described as the main cellular gauge of OXPHOS damage, as a result of the toxic by-products of ROS produced during OXPHOS [22]. In this context, oxidative damage induced by hypoxia and ROS generation might lead to genetic alterations in mtDNA and nuclear DNA (nDNA). This suggests that such injury could endanger mitochondrial biogenesis and lead to the accumulation of mutations in mitochondrial genome, cellular senescence, resistance to apoptosis, and tumor formation [23].

In addition, the mitochondrial genome harbors some characteristics in which it has been suggested that mtDNA is involved in tumorigenesis processes: (1) mtDNA has a higher mutational rate than nDNA. This is due to the oxidative environment of the mitochondrion. The ROS produce free radicals which act as powerful mtDNA mutagenic agents. In addition, mtDNA lacks histones (which nDNA have) that help prevent mutations [24]. (2) There are many mtDNA copies (typically, 100-1,000) per cell. Moreover, the replication of mtDNA is an independent event of S phase of the cell cycle [25]. (3) There exists an mtDNA repair mechanism, which is less rigorous than for nDNA, thereby leading to increased chances of mutational events [26].

To better understand the role of the mitochondrial genome in breast cancer progression, our group produced a series of breast tumor cell lines that were adapted to HNO concentrations via the donor DETA-NONOate [27]. We analyzed one of these cell lines, BT-20, for somatic mutations in the mitochondrial genome of seven subunits of Complex I (ND1, ND2, ND3, ND4, ND4L, ND5, and ND6) and a control region (Dloop) in both parent and HNO cell lines, and we studied the same mtDNA regions in 71 breast cancer specimens along with the corresponding noncancerous breast tissues. Herein, we report a correlation of the breast tumor cell line BT-20HNO with the patient data. BT-20-HNO cells represent an equivalent subset of the breast cancer patient population that also had these same mtDNA changes.

\section{Material and methods}

Cell culture

One breast tumor cell line was used in this study: BT-20 [28]. The BT-20 cell line was purchased from American Type Culture Collection (VA, USA). BT-20 was grown in minimal essential media (MEM). The media was supplemented with $10 \%$ fetal calf serum inactivated at $56{ }^{\circ} \mathrm{C}$ for $30 \mathrm{~min}, 100 \mathrm{U} /$ $\mathrm{mL}$ penicillin, $100 \mu \mathrm{g} / \mathrm{mL}$ streptomycin, $2 \mathrm{mM}$ L-glutamine, 
and $2.5 \mu \mathrm{g} / \mathrm{mL}$ Amphotericin B solution. Furthermore, it was additionally supplemented with $100 \mathrm{mM}$ MEM nonessential amino acids and $1 \mathrm{mM}$ sodium pyruvate (Cellgro, Inc., VA, USA). The human breast tumor cell line was grown in a humidified incubator at $37{ }^{\circ} \mathrm{C}$ and $5 \% \mathrm{CO}_{2}$. The corresponding $\mathrm{HNO}$ cell line was grown in the same specific conditions of the 'parent' cell lines from which it originated except that $600 \mu \mathrm{M}$ of NO donor was added to the media [27]. The media and all supplements were purchased from Invitrogen (CA, USA), excepted where noted above.

Human breast cancer tissues and DNA isolation

Breast cancers and the adjacent noncancerous mammary tissues were obtained and histologically confirmed from 71 patients with their consent at Institute Fernandes Figueira
Hospital, Fiocruz, Brazil. Furthermore, 30 random individuals without a history of breast cancer were used as a control population. All tissues were kept in liquid nitrogen immediately after surgical resection, according to a protocol approved by the medical ethics committee for conducting human research at the hospital. Total DNA of the breast tumor cell line BT-20, human tissues, and peripheral blood were extracted by phenol/chloroform/isoamyl alcohol $(\mathrm{pH} 8)$ according to previously published methods [29]. The final DNA was dissolved in sterile water and frozen at $-20{ }^{\circ} \mathrm{C}$ until it was used.

Somatic mutation analysis of NADH dehydrogenase and D-loop mitochondrial genome

NADH dehydrogenase and D-loop mtDNA were sequenced for the BT-20 breast tumor cell line and patient breast cancer

Table 1 Nucleotide sequences of the primers

\begin{tabular}{|c|c|c|c|c|}
\hline Number & DNA fragment & Primer sequence $\left(5^{\prime} \rightarrow 3^{\prime}\right)$ & Nucleotide position & Product length $(\mathrm{bp})$ \\
\hline \multirow[t]{2}{*}{1} & ND1aF & GAG CCC GGT AAT CGC ATA AAA C & $3,251-3,726$ & 476 \\
\hline & ND1aR & GAT TGT TTG GGC TAC TGC TCG & & \\
\hline \multirow[t]{2}{*}{2} & $\mathrm{ND} 1 \mathrm{bF}$ & TCAAACTACGCCCTGATCGG & $3,679-4,054$ & 376 \\
\hline & ND1bR & GTGCGTCATATGTTGTTCCTAGG & & \\
\hline \multirow[t]{2}{*}{3} & $\mathrm{ND} 2 \mathrm{aF}$ & ATGTTGGTTATACCCTTCCCGTA & $4,444-4,921$ & 478 \\
\hline & ND2aR & ACGTTTAGTGAGGGAGAGATTTG & & \\
\hline \multirow[t]{2}{*}{4} & $\mathrm{ND} 2 \mathrm{bF}$ & CСССАТСТCAАTCATATACCAA & $4,880-5,544$ & 665 \\
\hline & $\mathrm{ND} 2 \mathrm{bR}$ & AAGGCTCTTGGTCTGTATTTAACC & & \\
\hline \multirow[t]{2}{*}{5} & ND3F & CTT CCA ATT AAC TAG TTT TGA CAA CA & $10,019-10,708$ & 690 \\
\hline & ND3R & GAG ACT AGT AGG GCT AGG CCC AC & & \\
\hline \multirow[t]{2}{*}{6} & $\mathrm{ND} 4 \mathrm{aF}$ & TCCTCCCTACTATGCCTAGAAGG & $10,551-11,151$ & 601 \\
\hline & ND4aR & GCCAAGGTGGGGATAAGTGTG & & \\
\hline \multirow[t]{2}{*}{7} & $\mathrm{ND} 4 \mathrm{bF}$ & CATTCACAGCCACAGAACTAATCA & $11,085-11,758$ & 674 \\
\hline & ND4bR & GTTTGAGTTTGCTAGGCAGAATAG & & \\
\hline \multirow[t]{2}{*}{8} & ND5aF & CCCCATGTCTAACAACATGGC & $12,238-13,007$ & 770 \\
\hline & ND5aR & GATTTGCCTGCTGCTGCTAGG & & \\
\hline \multirow[t]{2}{*}{9} & $\mathrm{ND} 5 \mathrm{bF}$ & AACGCTAATCCAAGCCTCACC & $12,949-13,738$ & 790 \\
\hline & ND5bR & TGAGAAATCCTGCGAATAGGC & & \\
\hline \multirow[t]{2}{*}{10} & ND6F & CATTAAACGCCTGGCAGCC & $13,695-14,499$ & 805 \\
\hline & ND6R & TATTTAGGGGGAATGATGGTTGT & & \\
\hline \multirow[t]{2}{*}{11} & $\mathrm{D} 11 \mathrm{~F}$ & ATTACTGCCAGCCACCATGAA & $16,100-16,544$ & 445 \\
\hline & Dl1R & ACGTGTGGGCTATTTAGGCTTTA & & \\
\hline \multirow[t]{2}{*}{12} & $\mathrm{D} 12 \mathrm{~F}$ & CGTGAAATCAATATCCCGCAC & $16,411-262$ & 420 \\
\hline & $\mathrm{D} 12 \mathrm{R}$ & GGCTGTGCAGACATTCAATTG & & \\
\hline \multirow[t]{2}{*}{13} & $\mathrm{D} 13 \mathrm{~F}$ & CGCACCTACGTTCAATATTACAGG & $162-525$ & 364 \\
\hline & D13R & GGTGTGTGTGTGCTGGGTAGG & & \\
\hline \multirow[t]{2}{*}{14} & $\mathrm{NDF}$ & TCAAACTACGCCCTGATCGG & & 117 \\
\hline & NDR & GGAGAGGTTAAAGGAGCCACT & & \\
\hline \multirow[t]{2}{*}{15} & $\mathrm{ACTBF}$ & TTCCTTCCTGGGCATGGAGTC & & 109 \\
\hline & ACTBR & AGACAGCACTGTGTTGGCGTA & & \\
\hline
\end{tabular}

Core of primers used to sequence and real-time PCR 
DNA samples to screen for somatic mtDNA mutations. Thirteen overlapping DNA fragments ranging in size from $364 \mathrm{bp}$ to $805 \mathrm{bp}$ were generated by polymerase chain reaction (PCR) amplification spanning the NADH dehydrogenase and D-loop mitochondrial genome (Table 1). PCR was performed for 30 cycles in a $25-\mu \mathrm{L}$ reaction mixture containing $10-100 \mathrm{ng}$ DNA, $200 \mu \mathrm{M}$ of each dNTP, $0.1 \mu \mathrm{M}$ of each primer, $1.5 \mathrm{mM} \mathrm{MgCl} 2,1 \mathrm{U}$ of Taq DNA Polymerase recombination (Invitrogen, Inc.), and $2.5 \mu \mathrm{L}$ of $1 \times$ PCR Rxn buffer (Invitrogen, Inc.). PCR cycles consisted of 45-s denaturation at $94^{\circ} \mathrm{C}, 45$-s annealing at $58^{\circ} \mathrm{C}$, and 1 -min primer extension at $72^{\circ} \mathrm{C}$. PCR was performed in an ABI GeneAmp PCR System 9700 DNA thermal cycler (Applied Biosystems, Foster City, CA, USA). The PCR products were purified by enzymatic assay with ExoSAP kit (GE Healthcare) and sequenced with an ABI BigDye Terminator (version 3.1) cycle sequencing ready reaction kit and an ABI PRISM 3130 sequencer (Applied Biosystems, Foster City, CA, USA), according to the manufacturer's recommendation. Both forward and reverse DNA strands were used for DNA sequencing, and resequencing was used to confirm the mutations within each DNA fragment. DNA fragments from the parent and HNO cell lines, as well as noncancerous breast tissues and breast cancer specimens of the same patient, were analyzed. mtDNA sequences of the parent and HNO cell line were compared; any DNA sequence difference between the two cell lines was scored as a somatic mtDNA mutation. The same analysis was performed on both normal and tumor samples from patients. Both DNA fragments from the breast tumor cell lines were compared with the revised Cambridge Sequencing mtDNA reference [30]; any DNA sequence difference between the parent and HNO cell lines was scored as a polymorphism.

\section{Cloning NADH dehydrogenase gene and $\beta$-actin gene}

To construct the standard curves of quantified mtDNA copy number in the breast tumor cell lines and breast cancer population samples, we cloned one region of $N A D H$ dehydrogenase subunit 1 (ND1) gene and one region of $\beta$-actin $(A C T B)$ gene. These genes were cloned with a pGEM ${ }^{\circledR}-\mathrm{T}$ Easy Vector System (Promega, WI, USA) according to the manufacturer's recommendation.

Analysis of mtDNA content by quantitative real-time PCR

Determination of the mtDNA copy number of the BT-20 human breast tumor cell lines was carried out according to a previously reported method by Mambo et al. [31]. The 7500 real-time PCR system (Applied Biosystems, Foster City, CA, USA) was used to amplify $N D 1$ gene and $A C T B$ gene. Table 1 lists the core of primers used to amplify the respective DNA regions. qPCR was performed for 40 cycles in a $15 \mu \mathrm{L}$ reaction mixture containing 1-5 ng DNA template, $7.5 \mu \mathrm{L}$ SYBR
Green PCR Master Mix (Applied Biosystems, Foster City, CA, USA), and 25 pmol of each primer. qPCR cycles consisted of 10 -min initial denaturation at $95{ }^{\circ} \mathrm{C}, 15$-s denaturation at $95{ }^{\circ} \mathrm{C}$, and 1 -min annealing/extension at $60{ }^{\circ} \mathrm{C}$. For each PCR run, separate standard curves were generated from approximately ten serially diluted plasmids (pGEM ${ }^{\circledR}-\mathrm{T}$ Easy Vector Systems; Promega, WI, USA) containing PCR products for either mtDNA ND1 or $\beta$-actin gene fragment. The copy number of mtDNA ND1 region in each sample was then normalized against the $\beta$-actin gene to calculate the absolute mtDNA copy number. Each measurement was repeated in three independent experiments running in triplicate, and a nontemplate control was included in each experiment.

Immunohistochemistry

Immunohistochemistry using the anti-eNOS antibody (Abcam, Cambridge, MA, USA, catalog \# ab66127) was
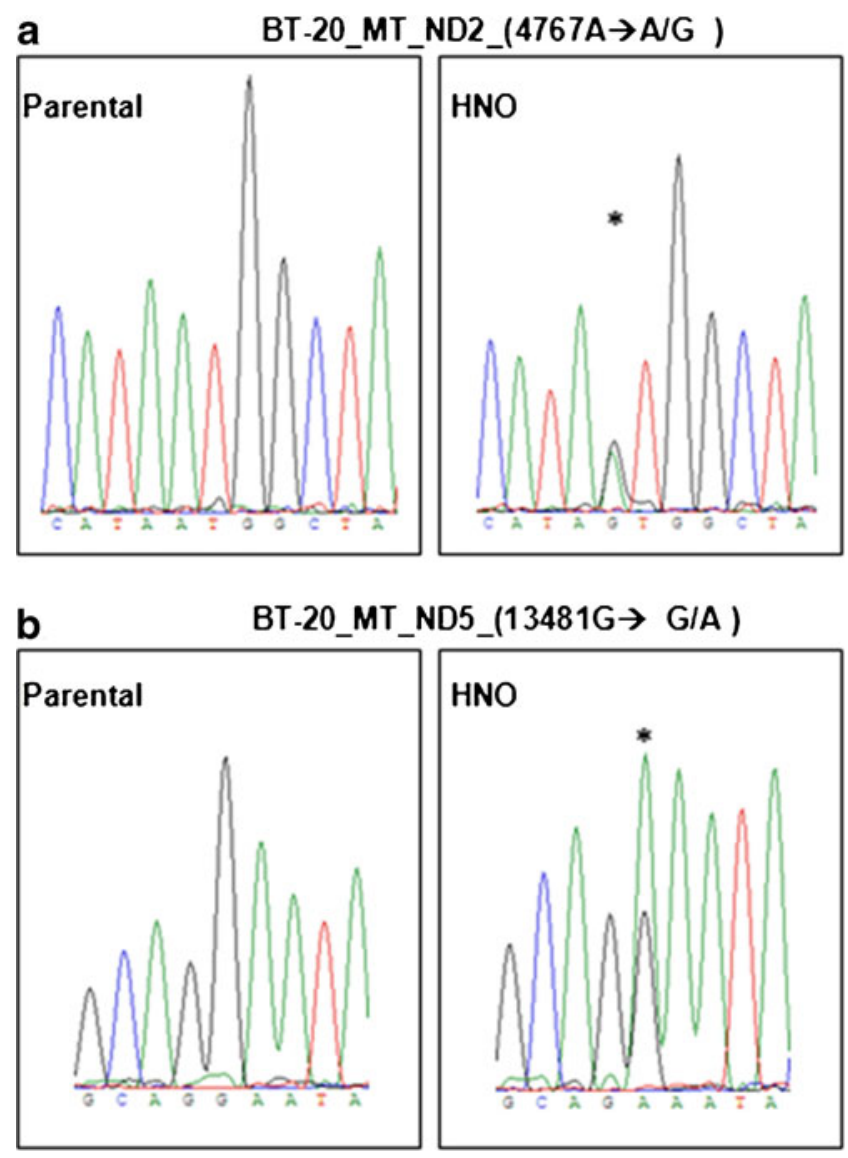

Fig. 1 Somatic mtDNA mutations A4767G and G13481A in BT-20HNO. Using direct sequencing methods, the A4767G mutation was detected in the breast tumor cell line adapted to increasing concentrations of high nitric oxide (NO) (a). The mutation caused a substitution of amino acid residue from methionine $(\mathrm{M})$ to valine $(\mathrm{V})$ in NADH dehydrogenase subunit 2 (ND2). The G13481A mutation was detected in the BT-20-HNO cell line (b). The mutation caused a substitution of amino acid residue from glycine $(\mathrm{G})$ to glutamic acid (E) in NADH dehydrogenase subunit 5 (ND5) 
Fig. 2 Somatic mtDNA mutations in the initiation replication site at nucleotide 57 and in a "hot spot" cytidine-rich D300-310 segment. Using direct sequencing methods, both mtDNA mutations 58 insertion $\mathrm{C}$ and 303:315 C(7-8)TC(6) were detected in the BT-20 HNO cell line (a and b) a
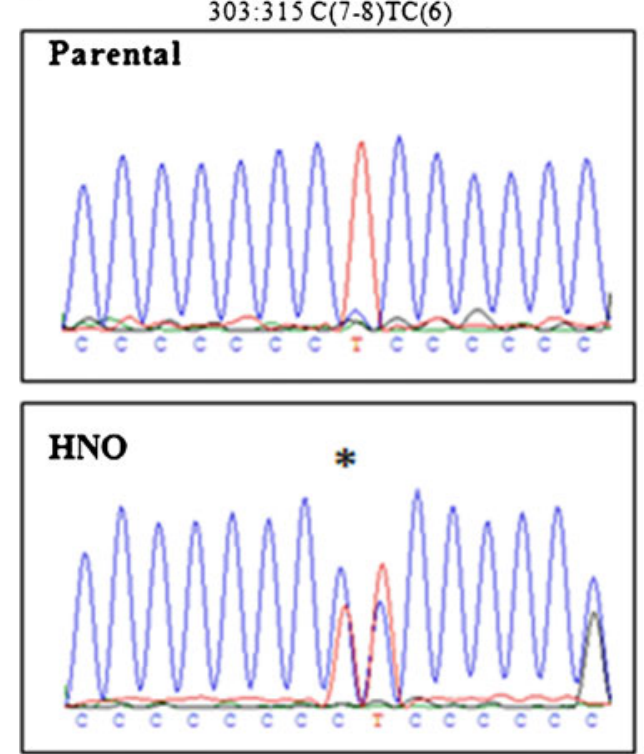

b
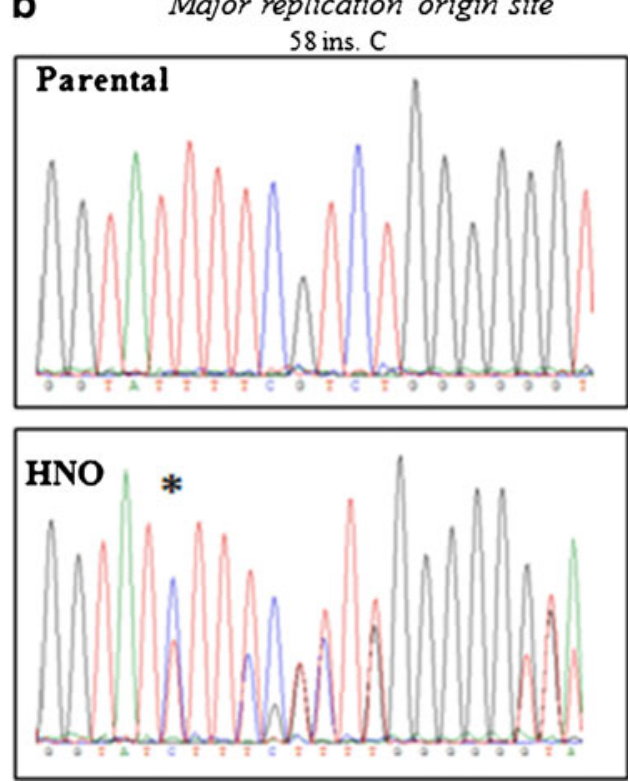

performed on a subset of the patients defined above, via a previously reported method.

Data analysis and statistics

Statistical analysis was performed using SigmaPlot version 11.0 (System Software, Inc., Chicago, IL, USA). The $t$ test (paired test) was used to compare the difference in mtDNA copy number between human breast tumor parent and HNO cell line, and between breast tumors and their corresponding nontumorous tissues.

\section{Results}

Somatic mtDNA mutations in parent/HNO breast tumor cell lines

In previous work, a human breast tumor cell line, BT-20, was adapted to increasing concentrations of the NO donor DETANONOate, up to $600 \mu \mathrm{M}$, over approximately 100 days.
Vesper et al. showed that although all the parent and HNO cells had the same morphologic appearance, HNO-adapted cells grew faster than their corresponding parent cells and were resistant to both nitrogen- and oxygen-based free radicals [27]. To confirm if the adaptation process might affect the mitochondrial genome, we herein carried out direct DNA sequence of the seven subunits of NADH dehydrogenase gene (ND1, ND2, ND3, ND4, ND4L, ND5, and ND6) and D-loop regions of mtDNA. Interestingly, four somatic mtDNA mutations not found in the parent cell line were found to be present in the BT-20-HNO cell line. Two of these somatic mutations, A4767A/G and G13481G/A, were found in the NADH dehydrogenase gene (Fig. 1). These mtDNA mutations might be potentially harmful mutations, but they are not lethal. The change of an amino acid occurred at a highly conserved position, and the substitution G13481G/A changes amino acids that were nonpolar to polar (negatively charged). The A4767G mutation in the NADH dehydrogenase subunit 2 (ND2) gene causes a substitution of the amino acid residue from methionine to valine, and the G13481A mutation in the $N A D H$ dehydrogenase subunit 5 (ND5) gene causes a
Fig. 3 Standard curves and mtDNA copy number in BT-20 cell lines. Using real-time PCR methods, two standard curves were constructed of $N A D H$ dehydrogenase subunit 1 (NDI) gene and $\beta$-actin $(A C T B)$ gene (a). The graph shows the mtDNA copy number in the BT-20 parent and the BT-20HNO cell line (b). $P$ values were calculated using twotailed paired $t$ tests $\left({ }^{*} p<0.042\right)$
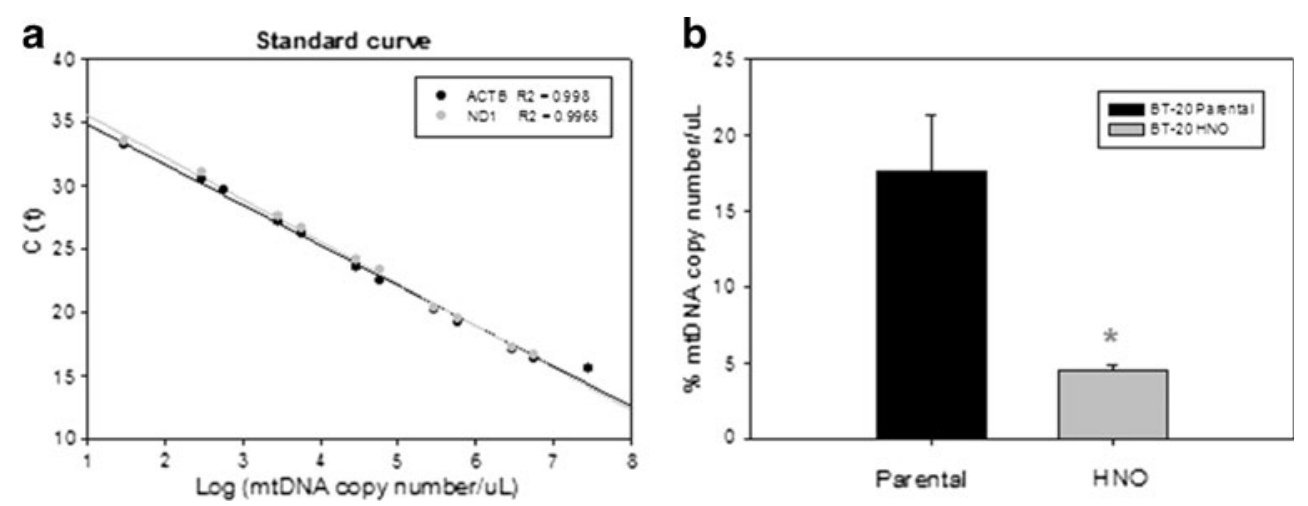
substitution of amino acid residue from glycine to glutamic acid (data not shown). The other two mtDNA points mutations were identified in the mtDNA initiation replication site at nucleotide 57 (58 insertion C; Fig. 2) [32] and at the "hot spot" cytidine-rich D300-310 segment 303:315 C(7-8)TC(6) (Fig. 2) [33].
mtDNA content

Quantitative real-time PCR was used to measure mtDNA in both the parent and the HNO cells. We selected one mitochondrial gene, $N D 1$, and one nuclear gene, $\beta$-actin. Standard curves for the mtDNA ND1 and

Table 2 Summary of the mtDNA mutations in the 71 primary breast carcinomas

\begin{tabular}{|c|c|c|c|c|c|c|}
\hline \multirow[t]{2}{*}{ Patient number } & \multicolumn{2}{|c|}{ D-loop mutation } & \multicolumn{2}{|c|}{ Mitochondrial genome } & \multirow[t]{2}{*}{ Mutation gene } & \multirow[t]{2}{*}{ Amino acid changes } \\
\hline & n.p. & Mutation & n.p. & Mutation & & \\
\hline P6 & $303: 315$ & $\mathrm{C}(8-9) \mathrm{TC}(6)$ & & & & \\
\hline \multirow[t]{2}{*}{ P8 } & 16,192 & $\mathrm{C} \rightarrow \mathrm{C} / \mathrm{T}$ & 5,169 & $\mathrm{C} \rightarrow \mathrm{C} / \mathrm{T}$ & ND2 & $\operatorname{Trp}(\mathrm{UGA}) \rightarrow \operatorname{Arg}(\mathrm{CGA})$ \\
\hline & & & 10,353 & $\mathrm{G} \rightarrow \mathrm{G} / \mathrm{A}$ & ND3 & $\mathrm{Ala}(\mathrm{GCC}) \rightarrow \operatorname{Thr}(\mathrm{ACC})$ \\
\hline P9 & 16,309 & $\mathrm{~A} \rightarrow \mathrm{A} / \mathrm{G}$ & & & & \\
\hline P10 & $303: 315$ & $\mathrm{C}(7-8) \mathrm{TC}(6)$ & & & & \\
\hline \multirow[t]{2}{*}{ P16 } & $303: 315$ & $\mathrm{C}(7-8) \mathrm{TC}(6)$ & & & & \\
\hline & 16,391 & $\mathrm{G} \rightarrow \mathrm{G} / \mathrm{A}$ & & & & \\
\hline P17 & 16,261 & $\mathrm{C} \rightarrow \mathrm{C} / \mathrm{T}$ & & & & \\
\hline P19 & $303: 315$ & $\mathrm{C}(7-8) \mathrm{TC}(6)$ & & & & \\
\hline P25 & 182 & $\mathrm{C} \rightarrow \mathrm{C} / \mathrm{T}$ & & & & \\
\hline P29 & & & 13,135 & $\mathrm{G} \rightarrow \mathrm{A}$ & ND5 & $\mathrm{Ala}(\mathrm{GCA}) \rightarrow \operatorname{Thr}(\mathrm{ACA})$ \\
\hline P32 & & & 10,500 & $\mathrm{G} \rightarrow \mathrm{G} / \mathrm{A}$ & ND4L & $\mathrm{Ala}(\mathrm{GCA}) \rightarrow \operatorname{Thr}(\mathrm{ACA})$ \\
\hline P33 & 139 & $\mathrm{~T} \rightarrow \mathrm{T} / \mathrm{C}$ & & & & \\
\hline P34 & 66 & $\mathrm{G} \rightarrow \mathrm{G} / \mathrm{T}$ & & & & \\
\hline P38 & & & 4,830 & $\mathrm{G} \rightarrow \mathrm{G} / \mathrm{A}$ & ND2 & Gly(GGC) $\rightarrow$ Ser(AGC) \\
\hline \multirow[t]{3}{*}{$\mathrm{P} 40$} & 294 & $\mathrm{~T} \rightarrow \mathrm{T} / \mathrm{C}$ & 10,265 & $\mathrm{~T} \rightarrow \mathrm{T} / \mathrm{C}$ & ND3 & Iso $\left(\mathrm{AUU}^{\mathrm{a}}\right) \rightarrow$ Iso(AUC) \\
\hline & & & 10,389 & $\mathrm{~T} \rightarrow \mathrm{T} / \mathrm{C}$ & ND3 & Leu1(UUA) $\rightarrow$ Leu2(CUA) \\
\hline & & & 14,410 & $\mathrm{G} \rightarrow \mathrm{G} / \mathrm{A}$ & ND6 & $\operatorname{Val}(\mathrm{GUC}) \rightarrow \operatorname{Val}(\mathrm{GUU})$ \\
\hline \multirow[t]{2}{*}{ P41 } & & & 13,809 & $\mathrm{C} \rightarrow \mathrm{C} / \mathrm{T}$ & ND5 & Leu(CUC) $\rightarrow$ Leu(CUU) \\
\hline & & & 13,809 & $\mathrm{C} \rightarrow \mathrm{T} / \mathrm{C}$ & ND5 & $\mathrm{Leu}(\mathrm{CUC}) \rightarrow \mathrm{Leu}(\mathrm{CUU})$ \\
\hline P47 & & & 10,522 & $\mathrm{G} \rightarrow \mathrm{G} / \mathrm{A}$ & ND4L & Gly(GGA) $\rightarrow$ Glu(GAA) \\
\hline P52 & & & 10,197 & $\mathrm{G} \rightarrow \mathrm{G} / \mathrm{A}$ & ND3 & $\mathrm{Ala}(\mathrm{GCC}) \rightarrow \operatorname{Thr}(\mathrm{ACC})$ \\
\hline P57 & $303: 315$ & $\mathrm{C}(8-9) \mathrm{TC}(6)$ & & & & \\
\hline \multirow[t]{2}{*}{ P59 } & $303: 315$ & $\mathrm{C}(7-8) \mathrm{TC}(6)$ & & & & \\
\hline & 338 & $\mathrm{C} \rightarrow \mathrm{C} / \mathrm{T}$ & & & & \\
\hline P61 & 215 & $\mathrm{~A} \rightarrow \mathrm{A} / \mathrm{G}$ & & & & \\
\hline P62 & $303: 315$ & $\mathrm{C}(8-9) \mathrm{TC}(6)$ & & & & \\
\hline P66 & & & 4,812 & $\mathrm{G} \rightarrow \mathrm{G} / \mathrm{A}$ & ND2 & $\operatorname{Val}(\mathrm{GUC}) \rightarrow \mathrm{Ile}(\mathrm{AUC})$ \\
\hline P69 & & & 10,506 & $\mathrm{~A} \rightarrow \mathrm{A} / \mathrm{G}$ & ND4L & $\operatorname{Thr}(\mathrm{ACC}) \rightarrow \mathrm{Ala}(\mathrm{GCC})$ \\
\hline P72 & $303: 315$ & $\mathrm{C}(7-8) \mathrm{TC}(6)$ & & & & \\
\hline \multirow[t]{3}{*}{ P74 } & $303: 315$ & $\mathrm{C}(7-8) \mathrm{TC}(6)$ & & & & \\
\hline & 16,291 & $\mathrm{C} \rightarrow \mathrm{C} / \mathrm{T}$ & & & & \\
\hline & 150 & $\mathrm{C}>\mathrm{T}$ & & & & \\
\hline P78 & $303: 315$ & $\mathrm{C}(7-8) \mathrm{TC}(6)$ & & & & \\
\hline P82 & & & 10,427 & $\mathrm{G} \rightarrow \mathrm{G} / \mathrm{A}$ & tRNA ${ }^{\text {Arg.(CGN) }}$ & \\
\hline P85 & $303: 315$ & $\mathrm{C}(7-8) \mathrm{TC}(6)$ & & & & \\
\hline
\end{tabular}

ND2 NADH dehydrogenase subunit 2, ND3 NADH dehydrogenase subunit 3, ND4L NADH dehydrogenase subunit 4L, ND5 NADH dehydrogenase subunit 5, ND6 NADH dehydrogenase subunit 6, n.p. nucleotide position

${ }^{a} \mathrm{AUU}$, isoleucine codon in the mitochondria genome

${ }^{\mathrm{b}}$ Total of somatic mtDNA mutations 39 
$\beta$-actin genes were constructed using clones of DNA from both genes in a concentration range between $1 \mathrm{ng}$ and $100 \mathrm{pg}$ (Fig. 3a). There was a 2.8-fold decrease in the mtDNA copy number in the BT-20-HNO cell line, relative to the BT-20 parent cell line (Fig. 3b).

Selection of mitochondrial genome/clone expansion

The concepts of homoplasmy and heteroplasmy are important in mitochondrial genome study. Homoplasmy refers to mtDNA in which all copies are the same, whereas heteroplasmy refers to a mixture of two or more mtDNAs. It is important to consider that during a disease process, there may be heteroplasmy between wild type and mutant genome. All mtDNA mutations identified for the BT-20HNO cell line, as well as those identified in the tumor samples of patients, were found to be heteroplasmic (Figs. 1 and 2, and Table 2).

As shown in Fig. 4, the heteroplasmy C10292T is present in both BT-20 parent and BT-20-HNO cells and represents a silent polymorphism in NADH dehydrogenase gene, subunit 3 . Intriguingly, the mitochondrial genome could suffer mtDNA selection after the adaptation process with high concentrations of NO. This mtDNA selection mimics a clone expansion, when two different populations of mtDNA, wild type and mutated, were selected after the treatment with high concentrations of NO.

Somatic mutations in mitochondrial genome of human breast cancers

We characterized 27 different somatic mtDNA mutations to NADH dehydrogenase and control region (D-loop) in 71 human breast cancer samples. Our results showed a high frequency of somatic mtDNA mutations in NADH dehydrogenase and a low frequency of somatic mtDNA mutations in D-loop when compared to data reported in studies of breast cancer [33-35]. Intriguingly, somatic mtDNA mutations were present in both breast cancers and adjacent noncancerous mammary tissues. Sequencing showed 14 somatic mutations in the coding region of mtDNAs in 11 breast cancer samples, and 13 other somatic mutations were present in the control region of mtDNAs in 19 breast cancer samples (Table 2). Among the 14 somatic mutations in the NADH dehydrogenase gene, 13 were heteroplasmic (G4812A, G4830A, T5169C, G10197A, T10265C, G10353A, T10389C, G10427A, G10500A, A10506G，G10522A，C13809T, and $\mathrm{G} 14410 \mathrm{~A})$ and one point mutation $(\mathrm{G} 13135 \mathrm{~A})$ was homoplasmic. Among the 11 breast cancer specimens with somatic mutations in the coding regions, three
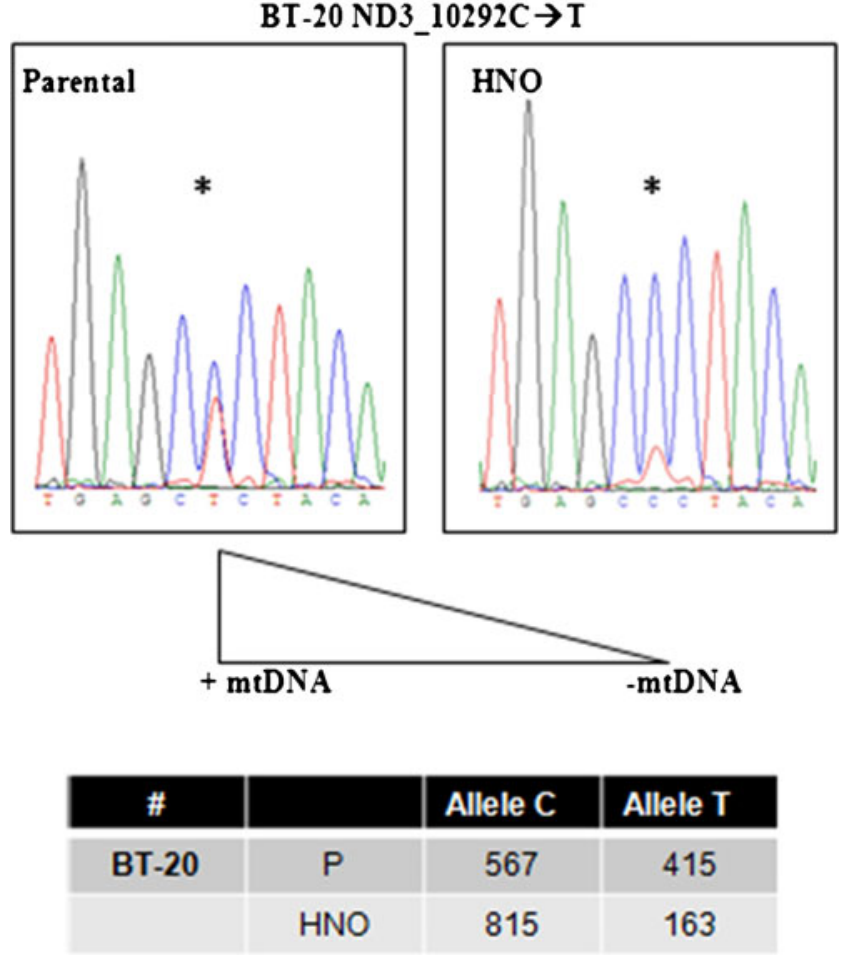

Fig. 4 Mitochondrial genome clone selected. Using direct sequencing methods, the C10292T polymorphism was detected in both the BT-20 parent and BT-20-HNO cell lines. This polymorphism is a silent nucleotide alteration in NADH dehydrogenase subunit 3 (ND3). After the long-term adaptation to increasing concentrations of $\mathrm{HNO}$, the wild type mtDNA was selected for BT-20-HNO cells

cases $(27.3 \%)$ were found to harbor somatic mutations in the D-loop of mtDNA.

Among the eight somatic mutations exclusively found in the breast cancer specimens, seven $(87.5 \%)$ mutations (G4830A, T5169C, G10197A, G10500A, A10506G, G10522A, and G13135A) were proposed to be potentially harmful mutations (data not shown). The first two resulted in the substitution of an amino acid that occurred at the highly conserved amino acid residues position. Also, all substitutions resulted in changes in amino acid characteristic of nonpolar to polar or vice-versa (data not shown). The G4830A mutation in the $N A D H$ dehydrogenase subunit 2 (ND2) gene causes a substitution of amino acid residue from glycine to serine. The $\mathrm{T} 5169 \mathrm{C}$ mutation in the $N A D H$ dehydrogenase subunit 2 (ND2) gene causes a substitution of amino acid residue from tryptophan to arginine. The G10197A mutation in the ND3 gene results in an amino acid substitution from alanine to threonine. Furthermore, the G10500A mutation in the $N D 4 L$ gene results in an amino acid substitution from alanine to threonine, while the A10506G mutation results in the ND4L gene in an amino acid substitution from threonine to alanine. The G10522A mutation in the $N D 4 L$ gene results in an 
amino acid substitution from glycine to glutamic acid. Finally, the homoplasmic mutation G13135A occurred in the NADH dehydrogenase subunit 5 (ND5) gene, which changes the amino acid from alanine to threonine. In addition, one mutation (G10427A) occurred at the noncoding nucleotides at $\mathrm{tRNA}^{\mathrm{Arg}}$; this somatic mutation, G10427A, is likely to alter the structure of the $\mathrm{T} \psi \mathrm{C}$ loop in the clover leaf secondary structure of tRNA $^{\text {Arg }}$. The most substituted amino acid mutations, which are likely harmful missense mutations, occurred at the highly conserved amino acid residues and altered the nature of the amino acid.

Somatic mutations in the D-loop link breast tumor cell line data with patient data

Concomitant presences of mutations in the D-loop region of mtDNA and p53 have been previously described in breast cancer patients. These mutations were significantly predominant in breast cancer tumors with poor prognosis, such as advanced stage/grade tumors and ER/ PR-negative tumors [36]. Our data with the BT-20 breast tumor cell line and a group of breast cancer patients suggests that when BT-20 cells are pressured to fully adapt to increasing concentrations of the NO donor DETA-NONOate, two mtDNA point mutations were generated (one in the mtDNA initiation replication site at nucleotide 57 and one at the "hot spot" cytidine-rich D300 310 segment 303:315 C(7-8)TC(6)). Interestingly, the same somatic mtDNA mutations were the most frequent mutations in cancer patients (14/71, $19.71 \%)$. In addition, six of 14 samples were p53 mutation-positive and $70 \%$ had poor prognosis (Fig. 5 and Table 3 ). Also, the breast tumor cell line and $\sim 85 \%$ of the patients had decreased mtDNA content.

\section{Immunohistochemistry}

Six of the 14 patients studied herein had somatic mutations that were identical to those seen in the BT-20-HNO cell line. Tissue samples of these patients were immunostained for
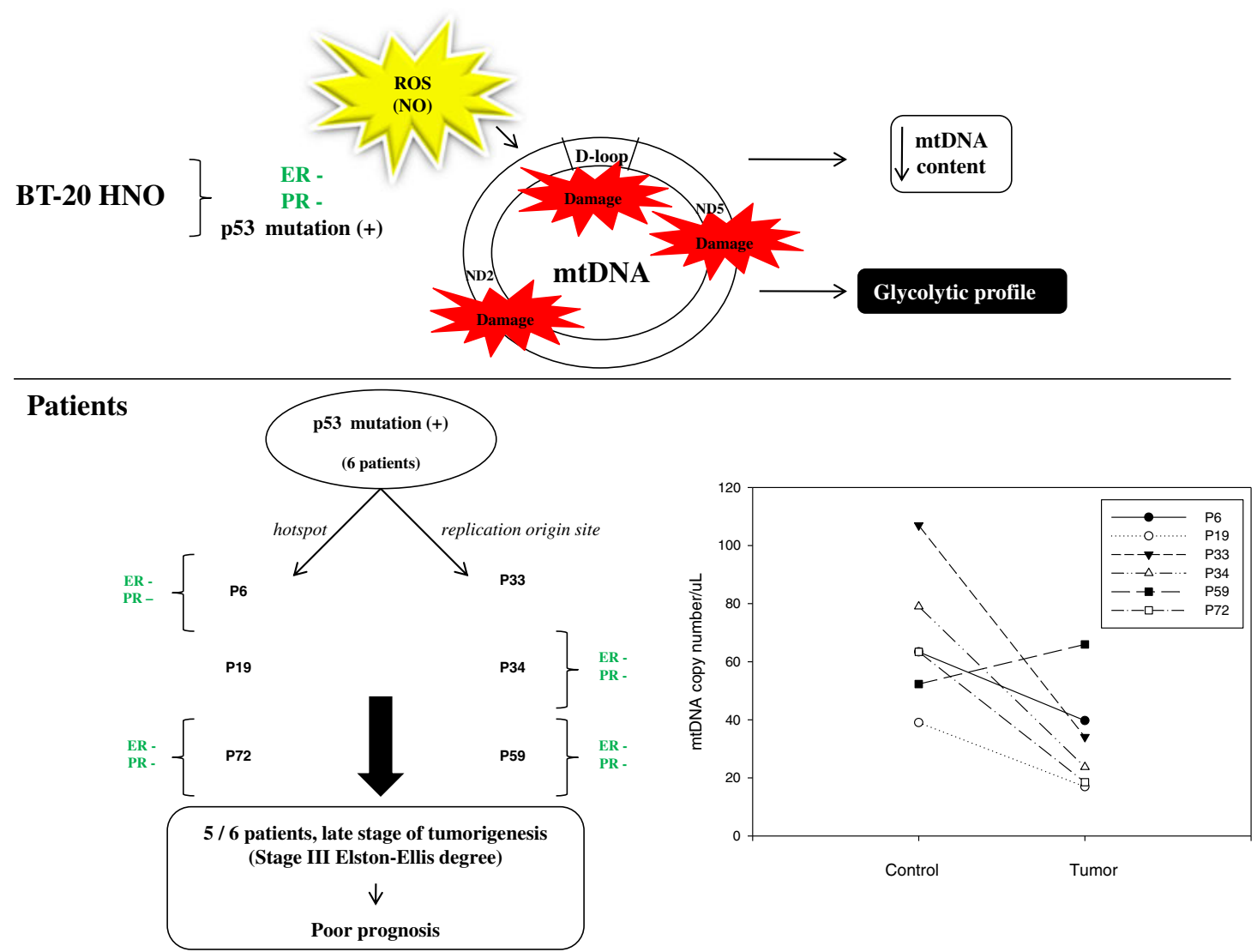

Fig. 5 Mitochondrial genome study linked BT-20 parent/HNO cell line results to patient data. The scheme summarizes mitochondrial genome mutations contributing to poor prognosis, such as advanced stage grade, the ER/PR negative, p53 mutated and decreased in mtDNA content. ROS $(N O)$ reactive oxygen species and nitric oxide, damage designated somatic mtDNA mutations, $E R^{-}$negative estrogen

receptor, $P R^{-}$negative progesterone receptor, $p 53+\mathrm{p} 53$-mutated gene. The scatter plots show mtDNA copy number in six breast cancer samples. Each breast tumor sample represents cancer specimens and corresponding noncancerous breast tissues from the same patient sample. $P$ values were calculated using two-tailed paired $t$ tests $(p<0.038)$ 
Table 3 Comparative analysis of the clinical/pathological characteristics of the BT-20-HNO cell line and 14 patient cases found to contain D-loop mutations

\begin{tabular}{|c|c|c|c|c|c|c|c|}
\hline $\begin{array}{l}\text { Patient } \\
\text { number }\end{array}$ & D-loop mutation & $\begin{array}{l}\text { mtDNA copy number } \\
\text { (tumor/normal) }\end{array}$ & $\begin{array}{l}\text { P53 } \\
\text { mutation }\end{array}$ & $\begin{array}{l}\text { eNOS } \\
\text { expression }\end{array}$ & $\begin{array}{l}\text { Estrogen } \\
\text { receptor (ER) }\end{array}$ & $\begin{array}{l}\text { Progesterone } \\
\text { receptor }(\mathrm{PR})\end{array}$ & $\begin{array}{l}\text { Elston } \\
\text { grade }\end{array}$ \\
\hline BT-20-HNO & $\begin{array}{l}303: 315 \text { C(7-8)TC(6) } \\
\text { Nucleotide } 57 \\
303: 315 \text { C(7-8)ТC(6) }\end{array}$ & Decreased & + & High & - & - & III \\
\hline P6 & & Decreased & + & Moderate/high & - & - & III \\
\hline P10 & & Increased & + & na & - & - & III \\
\hline P16 & & Increased & - & na & + & - & I \\
\hline P19 & & Decreased & + & Moderate/high & + & + & I \\
\hline P57 & & nd & na & na & na & na & na \\
\hline P59 & & Increased & + & nd & - & - & III \\
\hline P62 & & Increased & - & na & + & + & II \\
\hline P72 & & Decreased & + & Moderate/high & - & - & III \\
\hline P74 & & Decreased & - & na & - & - & III \\
\hline P78 & & Increased & - & na & + & + & II \\
\hline P85 & & Increased & - & na & + & + & II \\
\hline & Nucleotide 57 & & & & & & \\
\hline P33 & & Decreased & + & Moderate/high & + & + & III \\
\hline P34 & & Decreased & + & Moderate/high & - & - & III \\
\hline
\end{tabular}

nd no difference, $n a$ not analyzed

Bold: There are 5 patients with the same molecular and cellular cell line results

eNOS expression and found to have much stronger staining than the control tissue. Figure 6 shows an example of the intense staining observed. This result implies these patients had HNO-producing tumors.

\section{Discussion}

There are controversial technical aspects regarding the importance of mitochondria in cancer that have warranted skepticism [37], while other studies have displayed the importance of mitochondria in cancer biology [38, 39]. In this study, we have demonstrated that the mitochondrial genome plays an important role in tumor transformation and progression. In light of our data, these results support the correlation between our cell line model system and breast cancer patients.

Herein, we identified somatic mtDNA mutations that were present in the NADH dehydrogenase gene and in a control region of the mitochondrial genome in a human breast tumor cell line adapted to increasing concentrations of $\mathrm{HNO}$ and breast cancer specimens from patients (Figs. 1 and 2, and Table 2). BT-20-HNO cells and eight patients (8/ $71,11.2 \%$ ) were found to harbor somatic mtDNA mutations which change amino acids at highly conserved amino acid positions. These mutations may result in mitochondrial dysfunction of cancer cells, as previously suggested by Otto Warburg [40], which may lead, in turn, to a more aggressiveness phenotype. Studies of breast cancer patients have shown that germ line-inherited mutations in the NADH dehydrogenase (respiratory complex I) subunit 5 (ND5), $\mathrm{CYTb}$, and COX I genes supports the inherent dysfunction of mitochondrial respiration in patients with cancers which facilitates tumor growth. This supports the idea that ROS production may play an important role in oncogenesis through somatic mutations and changes to aerobic glycolysis [8].

According to Ralph et al., tumor cells that harbor mitochondrial dysfunction and increased ROS production might be sensitive to ROS-induced apoptosis. This evidence was not observed for normal cell lines [22]. In the current study, as well as in earlier [27] and accompanying manuscripts [41, 42] studying the BT-20-HNO cell line model system, multiple aberrations were identified in the cellular function of the BT20-HNO cell line compared to the parent BT-20 cell line (greater proliferation, different gene expression profiles, $\mathrm{p} 53$ mutations, more prone to use of the glycolytic pathway, and resistance to the apoptosis-inducing drug salinomycin). Collectively, these results suggest that ROS may induce mtDNA somatic mutations in the BT-20-HNO cell line.

The D-loop region is associated with a control site for mtDNA transcription and replication. According to Yu et al., 

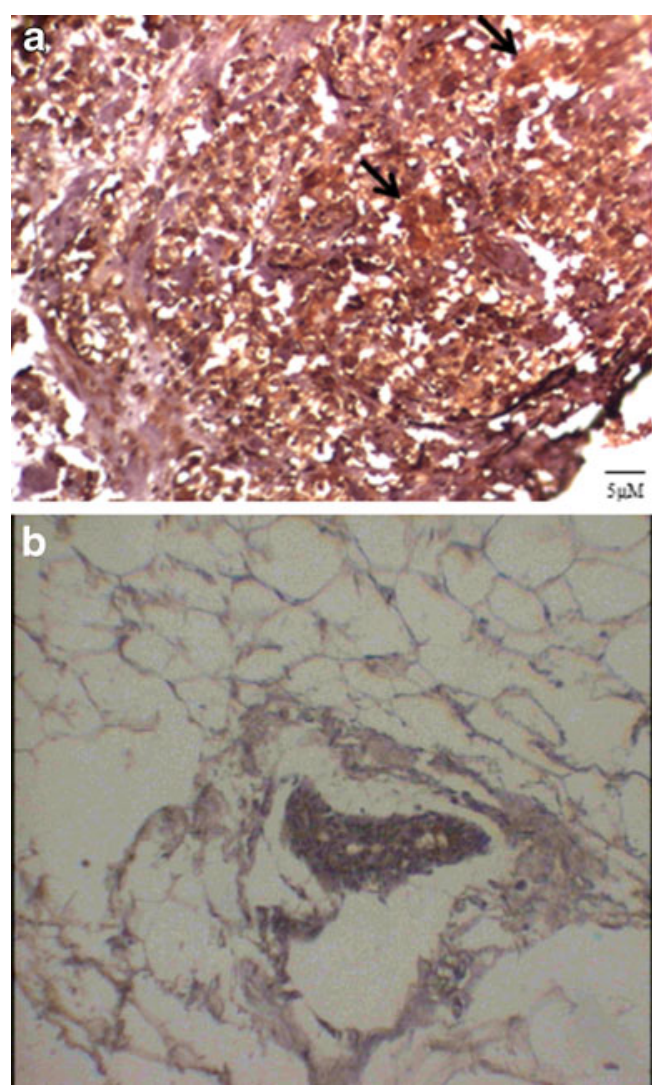

Fig. 6 a Representative image of immunohistochemical staining for eNOS expression, from one of the six patients which harbored the same mutation as BT-20-HNO. The black arrows indicate eNOS markers. b Negative control image. $\times 200$

mutations in this region might cause a decrease in the copy number in breast cancer patients [43]. We observed somatic mutations in the D-loop region in the BT-20-HNO cell line and in a group of breast cancer patients (14/71, $19.71 \%)$. In fact, D-loop mutations were identified in the mtDNA initiation replication site at nucleotide 57 and the "hot spot" cytidine-rich D300-310 segment 303:315 C(7-8)TC(6) (Fig. 2 and Table 2). These mutations could be associated with observed decreased in mtDNA content seen in the BT$20 \mathrm{HNO}$ cell line (2.8-fold), as well as in six of 14 patients samples, $p<0.038$ (Figs. 3b and 5). According to Ralph et al., the sites of both of these mutations may be important in regulating the mtDNA copy number. However, the exact effects of these mutations on the mtDNA copy number in tumors are still unclear and can result in either up- or downregulation of copy number. [22]. Loss of mtDNA copy number control is associated with aging [44] and breast cancer [7] and is likely to be linked to either nDNA or mtDNA mutations. This suggests our model cell line system might be important to understanding the role of the mitochondrial genome in the tumorigenesis process.

Tissue samples tested from the six cancer patients possessing the same mutations as were found in the BT-20-HNO cell line were all found to exhibit high eNOS expression. Furthermore, each of the six patients exhibited a p53 mutation [42], and four had poor outcome (Fig. 5 and Table 3). Heyne et al. and Achanta et al. suggested that somatic mtDNA mutations and a subsequent decrease in mtDNA copy number may also originate from dysfunction of the $p 53$ gene. It was recently reported that p53 plays an important role in maintaining mitochondrial genetic stability via the interaction with mtDNA polymerase $\mathrm{g}[45,46]$. As suggested by Zhou et al., neoplastic cells under selection pressure in head and neck cancers could acquire mutations in both mtDNA and the $p 53$ gene in the tumor microenvironment, resulting in an increased survival advantage and increased proliferation [47].

The results in this study suggest that the BT-20-HNO cell line can serve as a novel tool to study, as it reflects what is seen in some primary breast tumors. Furthermore, BT-20HNO might be associated with a group of patients that harbor the same characteristics as seen in patients with Dloop and p53 concomitant mutation patients. It is important to note that there are likely many more mutations occurring in both patients progression of cancer and during cell line adaptation. These mutations may be lethal and, therefore, not seen in either case. Nevertheless, the naturally HNO-producing patient tumors studied here and the use of $\mathrm{NO}$ in the cell culture model resulted in the same mutations. This finding supports the idea that NO is a driving force in breast cancer.

As a result of adaptation to NO by BT-20, a more aggressive phenotype, similar to what is seen in patients, is observed. The similarities between a subpopulation of breast cancer patients studied here and the BT-20-HNO cell line suggests that for a certain subset of the patient population, NO may, in fact, be the driving force leading cells to become more aggressive. These results reinforce the idea that the BT-20-HNO cell line is a good model system to study mitochondrial genome in cancer. In conclusion, the positive association between the BT-HNO cell line and the patient data reported herein supports the idea that $\mathrm{NO}$ is involved in breast cancer progression. Therefore, BT-20-HNO may be a potential tool to study the role of $\mathrm{NO}$ in the mitochondrial genome changes in breast cancer.

\section{References}

1. Hancock JT. The role of redox mechanisms in cell signalling. Mol Biotechnol. 2009;43(2):162-6.

2. Wallace DC. Mitochondria as chi. Genetics. 2008;179(2):727-35.

3. Clay Montier LL, Deng JJ, Bai Y. Number matters: control of mammalian mitochondrial DNA copy number. J Genet Genomics. 2009;36(3):125-31.

4. Larsson NG. Somatic mitochondrial DNA mutations in mammalian aging. Annu Rev Biochem. 2010;79:683-706. 
5. Wallace DC. A mitochondrial paradigm of metabolic and degenerative diseases, aging, and cancer: a dawn for evolutionary medicine. Annu Rev Genet. 2005;39:359-407.

6. Chatterjee A, Mambo E, Sidransky D. Mitochondrial DNA mutations in human cancer. Oncogene. 2006;25(34):4663-74.

7. Lee HC, Wei YH. Mitochondrial DNA instability and metabolic shift in human cancers. Int J Mol Sci. 2009;10(2):674-701.

8. Lu J, Sharma LK, Bai Y. Implications of mitochondrial DNA mutations and mitochondrial dysfunction in tumorigenesis. Cell Res. 2009;19(7):802-15.

9. Thomsen LL, et al. Nitric oxide synthase activity in human breast cancer. Br J Cancer. 1995;72(1):41-4.

10. Bentz BG, et al. Nitric oxide synthase type 3 is increased in squamous hyperplasia, dysplasia, and squamous cell carcinoma of the head and neck. Ann Otol Rhinol Laryngol. 1999;108(8):781-7.

11. Ambs S, et al. Frequent nitric oxide synthase- 2 expression in human colon adenomas: implication for tumor angiogenesis and colon cancer progression. Cancer Res. 1998;58(2):334-41.

12. Bentz BG, et al. Endothelial constitutive nitric oxide synthase (ecNOS) localization in normal and neoplastic salivary tissue. Head Neck. 1998;20(4):304-9.

13. Wink DA, et al. The multifaceted roles of nitric oxide in cancer. Carcinogenesis. 1998;19(5):711-21.

14. Glynn SA, et al. Increased NOS2 predicts poor survival in estrogen receptor-negative breast cancer patients. J Clin Invest. 2010;120 (11):3843-54

15. Bentz BG, Haines 3rd GK, Radosevich JA. Increased protein nitrosylation in head and neck squamous cell carcinogenesis. Head Neck. 2000;22(1):64-70.

16. Thomas DD, et al. The chemical biology of nitric oxide: implications in cellular signaling. Free Radic Biol Med. 2008;45(1):18-31.

17. Jenkins DC, et al. Roles of nitric oxide in tumor growth. Proc Natl Acad Sci U S A. 1995;92(10):4392-6.

18. Koufman JA, Burke AJ. The etiology and pathogenesis of laryngeal carcinoma. Otolaryngol Clin North Am. 1997;30(1):1-19.

19. Moller P, et al. Air pollution, oxidative damage to DNA, and carcinogenesis. Cancer Lett. 2008;266(1):84-97.

20. Brandon M, Baldi P, Wallace DC. Mitochondrial mutations in cancer. Oncogene. 2006;25(34):4647-62.

21. Wallace DC. Why do we still have a maternally inherited mitochondrial DNA? Insights from evolutionary medicine. Annu Rev Biochem. 2007;76:781-821.

22. Ralph SJ, et al. The causes of cancer revisited: "mitochondrial malignancy" and ROS-induced oncogenic transformation-why mitochondria are targets for cancer therapy. Mol Aspects Med. 2010;31(2):145-70.

23. Chandra D, Singh KK. Genetic insights into OXPHOS defect and its role in cancer. Biochim Biophys Acta. 2011;1807(6):620-5.

24. Todorov IN, Todorov GI. Multifactorial nature of high frequency of mitochondrial DNA mutations in somatic mammalian cells. Biochemistry (Mosc). 2009;74(9):962-70.

25. Attardi G, Schatz G. Biogenesis of mitochondria. Annu Rev Cell Biol. 1988;4:289-333.

26. Liu P, Demple B. DNA repair in mammalian mitochondria: much more than we thought? Environ Mol Mutagen. 2010;51(5):41726.

27. Vesper BJ, et al. Long-term adaptation of breast tumor cell lines to high concentrations of nitric oxide. Tumor Biol. 2010;31(4):26775 .
28. Lasfargues EY, Ozzello L. Cultivation of human breast carcinomas. J Natl Cancer Inst. 1958;21(6):1131-47.

29. Blin N, Stafford DW. A general method for isolation of high molecular weight DNA from eukaryotes. Nucleic Acids Res. 1976;3(9):2303-8.

30. Anderson S, et al. Sequence and organization of the human mitochondrial genome. Nature. 1981;290(5806):457-65.

31. Mambo E, et al. Tumor-specific changes in mtDNA content in human cancer. Int J Cancer. 2005;116(6):920-4.

32. Fish J, Raule N, Attardi G. Discovery of a major D-loop replication origin reveals two modes of human mtDNA synthesis. Science. 2004;306(5704):2098-101.

33. Tan DJ, Bai RK, Wong LJ. Comprehensive scanning of somatic mitochondrial DNA mutations in breast cancer. Cancer Res. 2002;62(4):972-6.

34. Gasparre G, et al. Disruptive mitochondrial DNA mutations in complex I subunits are markers of oncocytic phenotype in thyroid tumors. Proc Natl Acad Sci U S A. 2007;104 (21):9001-6.

35. Hung WY, et al. Somatic mutations in mitochondrial genome and their potential roles in the progression of human gastric cancer. Biochim Biophys Acta. 2010;1800(3):264-70.

36. Gochhait S, et al. Concomitant presence of mutations in mitochondrial genome and p53 in cancer development - a study in north Indian sporadic breast and esophageal cancer patients. Int J Cancer. 2008;123(11):2580-6.

37. Salas A, et al. A critical reassessment of the role of mitochondria in tumorigenesis. PLoS Med. 2005;2(11):e296.

38. Czarnecka AM, et al. Molecular oncology focus-is carcinogenesis a 'mitochondriopathy'? J Biomed Sci. 2010;17:31.

39. Bayona-Bafaluy MP, et al. Maternally inherited susceptibility to cancer. Biochim Biophys Acta. 2011;1807(6):643-9.

40. Warburg O. On respiratory impairment in cancer cells. Science. 1956;124(3215):269-70.

41. Vesper BJ, Onul A, Haines III GK, et al. Part I. Molecular and cellular characteristics of high nitric oxide-adapted human breast adenocarcinoma cell lines. Tumor Biol. 2012. doi:10.1007/ s13277-012-0530-0.

42. De Vitto H, Mendonça BS, Elseth KM, et al. Part III. Molecular changes induced by high nitric oxide adaptation in human breast cancer cell line BT-20 (BT-20-HNO): a switch from aerobic to anaerobic metabolism. Tumor Biol. 2012. doi:10.1007/s13277012-0564-3.

43. Yu M, et al. Reduced mitochondrial DNA copy number is correlated with tumor progression and prognosis in Chinese breast cancer patients. IUBMB Life. 2007;59(7):450-7.

44. Laderman KA, et al. Aging-dependent functional alterations of mitochondrial DNA (mtDNA) from human fibroblasts transferred into mtDNA-less cells. J Biol Chem. 1996;271(27):15891-7.

45. Heyne K, et al. Identification of a putative p53 binding sequence within the human mitochondrial genome. FEBS Lett. 2004;578(12):198-202.

46. Achanta G, et al. Novel role of p53 in maintaining mitochondrial genetic stability through interaction with DNA Pol gamma. EMBO J. 2005;24(19):3482-92.

47. Zhou S, et al. Frequency and phenotypic implications of mitochondrial DNA mutations in human squamous cell cancers of the head and neck. Proc Natl Acad Sci U S A. 2007;104 (18):7540-5. 